\title{
ÍNTIMOS ARQUIPÉLAGOS: LA AFORÍSTICA EN CADERNOS DE JOÃO DE ANÍBAL MACHADO Y LA POÉTICA DE LA ARCHIPELIZACIÓN
}

\author{
Miriam Lay Brander \\ Universität Konstanz \\ miriam.lay-brander@uni-konstanz.de
}

\section{RESUMEN / ABSTRACT}

Centrado en la obra aforística Cadernos de João (1957) del escritor brasileño Aníbal Machado, el presente artículo reflexiona sobre la relación entre el aforismo y una poética del archipiélago cuyos rasgos han sido trazados por Gastón Bachelard, los surrealistas franceses y, sobre todo, por Edouard Glissant. Postulamos la tesis de que Cadernos de João puede considerarse como obra precursora de una escritura aforística postcolonial que tiende a lo intuitivo, lo imprevisto y lo fragmentario, reflejando así las características de un mundo en estado de archipelización.

PALABRAS Clave: Aníbal Machado, literatura brasileña, aforismo, poética de la archipelización.

Based on the aphoristic work Cadernos de João (1957) by Brazilian writer Aníbal Machado, this article reflects on the relationship between aphorism and the poetics of archipelization whose main features have been outlined by Gaston Bachelard, the French Surrealists, and most notably by French Caribbean writer Edouard Glissant. We postulate that Cadernos de João anticipates an aphoristic postcolonial writing inclined to the intuitive, the unexpected, and the fragmentary, thus reflecting a world in a condition of archipelization.

KEY WORDS: Aníbal Machado, Brazilian literature, aphorism, poetics of archipelization. 
Mapa irregular do nosso descontínuo interior com os fragmentos, vozes, reflexões, imagens de lirismo e revolta-inclusive amostras de cerâmica verbal-dos muitos personagens imprecisos que o animam. Afloramento de íntimos arquipélagos, luzir espaçado das constelacões predominantes...

O autor apenas se reserva o direito de administrar o seu próprio caos e de impor-lhe certa ordem na tranqüilidade formal das palavras (CJ 17) ${ }^{1}$.

Aníbal Machado (1894-1964) ocupa un lugar destacado dentro del (post) modernismo brasileño. Busca, como uno de los representantes de la poesía postmodernista inaugurada por Carlos Drummond de Andrade, un camino individual para seguir desarrollando las formas de expresión modernistas. La obra de Aníbal Machado apenas puede clasificarse dentro de los movimientos literarios de su tiempo, sin embargo, tiene en común con la nueva literatura brasileña la característica de crear un discurso contra el orden social sin adoptar una determinada posición ideológica.

Autor de varios cuentos escritos a partir de 1944 y reunidos en el volumen A morte da Porta-Estandarte e Outras Historias y de la novela João Ternura, ambos publicados póstumamente en 1965, Aníbal Machado recrea en Cadernos de João (1957) el pensamiento desarrollado en sus obras previas $\mathrm{y}$ posteriores, que pueden considerarse un retrato de la vida interior de su autor. En este sentido, Cadernos de João muestra los rasgos de un intimismo que viene surgiendo en la literatura brasileña a partir de los años 30 y cuyas tendencias psicológicas tematizan el conflicto entre el individuo y la sociedad, presentando la escala de sentimientos que la vida moderna suscita en el interior del sujeto. Se trata de una inspección que, a veces, se sumerge en las zonas del sueño y de lo irreal, creando una continuidad entre un realismo interior, comprometido con lo verosímil, y el surrealismo (Bosi 388).

El presente artículo busca demostrar que en Cadernos de João el aforismo tiene las características de una escritura archipélica. Se funden en esta colección de aforismos dos de los elementos centrales del pensamiento del filósofo francés Gastón Bachelard, la fulguración de la imagen poética $4^{\mathrm{a}}$ ed., 2004.

En el presente trabajo se cita de Cadernos de João. Rio de Janeiro: José Olympio, 
y el agua como uno de sus fundamentos fenomenológicos. Su poética del archipiélago, a su vez, anticipa ciertos rasgos de la concepción archipélica que el teórico y escritor caribeño Edouard Glissant trazará en los años noventa. En la primera parte de nuestro análisis señalaré los rasgos comunes que muestra la aforística de Machado con el pensamiento archipélico de Glissant, Bachelard y los surrealistas franceses. En la segunda parte, ejemplificaré esas reflexiones, clasificando la producción aforística de Machado en archipiélagos semánticos, formales y gráficos. Finalmente, plantearé la pregunta para saber si el aforismo moderno en general, y sobre todo en el contexto postcolonial, puede considerarse como género archipélico trazando, a partir de Cadernos de João, algunas características fundamentales de este género.

\section{ANÍBAL MACHADO Y LA POÉTICA DEL ARCHIPIÉLAGO}

En el breve prólogo de Cadernos de João ya destaca la metáfora del archipiélago: "Afloramento de íntimos arquipélagos, luzir espaçado das constelacões predominantes..." (CJ 17). Esta imagen caracteriza los aforismos de Machado, que se describen como constelaciones poéticas surgiendo del interior humano, igual que las islas de un archipiélago salen a la superficie de un mar infinito e incontrolable. Más allá de ser solo una imagen de la producción poética en Cadernos de João, la metáfora archipélica une la obra de Machado con todo un programa poético, aunque éste se formulará solo algunas décadas más tarde. En Introduction à une poétique du divers (1995), Edouard Glissant distingue entre dos formas de pensamiento: el 'pensamiento continental' que controla legítimamente los movimientos -no solo literarios- del mundo, sin tomar en cuenta la emergencia de un 'pensamiento archipélico', “une autre forme de pensée, plus intuitive, plus fragile, menacée, mais accordée au chaos-monde et à ses imprévus” (Glissant, Introduction 43). Y precisa: "J'appelle cette pensée une pensée 'archipélique', c'est-à-dire une pensée non systématique, inductive, explorant l'imprévu de la totalité-monde et accordant l'écriture à l'oralité et l'oralité à l'écriture" (Glissant, Introduction 43-44). En esta concepción archipélica subyace la conexión de dos características contradictorias: el aislamiento insular y la unión del conjunto (Joubert 318). De ahí los rasgos que Glissant atribuye al pensamiento archipélico: a la intuición y lo no sistemático, añade en Traité du Tout-Monde (1997) lo inesperado y la apertura (Glissant, Traité 231). La similitud de estas características con los términos en los que Machado describe 
la formación de la imagen poética, como "afloramento" (CJ 17) o "aparição" (CJ 20), salta a la vista. Para Machado, la superficie fragmentada, visible del pensamiento refleja un interior atomizado a su vez, donde surgen, igual a las islas de un archipiélago dispersas en el mar, "fragmentos, vozes, reflexões, imagens de lirismo e revolta" (CJ 17). Estos "íntimos arquipélagos", el autor los somete a un orden por medio de la "tranqüilidade formal das palavras", o sea, en el caso de Cadernos de João, los expresa con fragmentos verbales que adoptan la forma de aforismos.

Las dos categorías del pensamiento archipélico: el aislamiento de las islas individuales y la continuidad invisible entre ellas, han sido formuladas -aunque sin vinculación directa con la metáfora archipélica-, en términos de la imaginación poética por Gastón Bachelard (1884-1962), uno de los pensadores destacados del modernismo y contemporáneo de Aníbal Machado:

Las fuerzas imaginantes de nuestro espíritu se desenvuelven sobre dos ejes muy diferentes. Unas cobran vuelo ante la novedad; se recrean con lo pintoresco, con lo vario, con el acontecimiento inesperado. La imaginación animada por ellas siempre tiene una primavera que describir. Lejos de nosotros, en la naturaleza, ya vivientes, producen flores.

Las otras fuerzas imaginantes ahondan en el fondo del ser; quieren encontrar en el ser a la vez lo primitivo y lo eterno. Dominan lo temporal y la historia. En la naturaleza, en nosotros y fuera de nosotros, producen gérmenes; gérmenes cuya forma está fijada en una sustancia, cuya forma es interna (Bachelard 7, cursiva en el original).

Los dos ejes inseparables de la imaginación que define Bachelard se corresponden perfectamente con las dos dimensiones del archipiélago, tal y como las describe Machado. Por una parte, la emergencia de las islas que salen a la superficie del océano ("Afloramento de íntimos arquipélagos, luzir espaçado das constalacões predominantes", CJ 17) representando lo fulgurante que cristaliza en la creación artística, y, por la otra, las profundidades del mar interior, donde se entremezclan "fragmentos, vozes, reflexões, imagens de lirismo e revolta [...] dos muitos personagens imprecisos" que lo animan. Para convertirse en obra capaz de seducir al lector, es necesario que la imaginación abandone las profundidades de la intimidad y se cristalice en una superficie que tiende a las formas, los colores y la metamorfosis (Bachelard 8). La imaginación no puede ser productiva hasta no fundirse en la realización concreta, hasta que la esencia profunda de la imaginación no se instale en 
un rango de temporalidad. Es precisamente esta "poética del instante, la emergencia permanente de un aire fresco de renovación epifánica” (Salazar Quintana 3) la que se muestra en los aforismos de Machado cuando habla de "a força de uma aparição" (CJ 20) o, más precisamente, de la súbita aparición de la imagen poética:

A imagem poética, em súbita aparição, já vem com os ritmos orgânicos que a prendem a todo o sistema do Universo" (CJ 108).

En el breve prólogo que inaugura Cadernos de João, Machado utiliza las metáforas espaciales del mapa y del archipiélago para describir la imaginación creativa. Más adelante sigue desarrollando la noción de una cartografía interior, oponiendo al "mapa irregular de nosso descontinuo interior" (CJ 17) una técnica cartográfica que excluye lo imprevisto, creando un espacio donde "tudo está cartografado e numerado" (CJ 55). Esta distinción se une sin dificultad con la oposición glissantiana entre el pensamiento archipélico, frágil e imprevisible, y el pensamiento continental, que somete el mundo con la ayuda de las técnicas cartográficas modernas.

Más allá de describir la creación poética en términos espaciales, Machado le atribuye al espacio interior la dimensión temporal inherente a la distinción efectuada por Bachelard entre la novedad y lo inesperado de las fuerzas imaginantes y su fondo eterno. Varios aforismos de Machado llevan el título "O verbo no infinito" (CJ 20, 71, 72, 73), que exprime la dialéctica entre la constancia del espacio interior y las erupciones creativas del espíritu:

Elevar a temperatura do espíritu ao nivel de fusão dos resíduos calcificados; purificar os sentidos até que o Universo se deixe surpreender em seu estado de virginidade original; dilatar as fronteiras de nosso espaço interior, não por ocupação colonizadora, mas excitando ao vôo os pássaros nele adormecidos; aquiecer ao apelo numeroso das coisas; promover à condição de árvore o que dentro de nós se esfria em pedra, e à condição de vento o que se esgalha em árvore: ritos preparatórios, íntimas providências, preliminares silenciosas à chegada da Poesía (CJ 72).

Según Machado, hay que preparar el interior humano, en primer lugar, pasivo ("adormecido"), hasta que sea capaz de recibir impulsos del universo circundante ("aquiecer ao apelo numeroso das coisas") que lo animan ("excitando ao vôo") a la poesía. Si la parte intemporal del espacio interior, "O sentimento do absoluto, do intemporal, do permanente" (CJ 23), no se 
frecuenta y se cultiva, se convierte en un desierto donde solo los místicos y los contemplativos pueden sobrevivir:

Há no espírito uma zona de silêncio que funciona longe e à revelia da nossa atividade imediata.

Se não a freqüentas e cultivas, vira cripta mortuária.

Inútil então esperar dela qualquer socorro (CJ 112).

A dicho elemento eterno y silencioso del espíritu, Machado le opone "o sentimento dramático do movimento" (CJ 23), que incluye lo provisorio, el llegar-a-ser, que también forma parte del pensamiento archipélico glissantiano. $\mathrm{Si}$, al principio, el movimiento de los pensamientos deja al hombre en un estado de fluctuación sin orientación, sus fuerzas centrípetas le permiten formar "um Universo alimentado por energias humanas e telúricas em constante transformação e metamorfose" (CJ 23), en que el hombre empieza a descubrirse a sí mismo.

Aparte de ilustrar la relación entre el "verbo" fulgurante y su fuente interior e intemporal, los dos aforismos que acaban de citarse ejemplifican el nexo creador que Machado identifica entre el universo y la imagen poética-nótese que "Universo" y "Poesía” se escriben con mayúsculas-, vinculación que también establece Bachelard. Para él, los fundamentos fenomenológicos de la imaginación creativa se basan en los cuatro elementos de la filosofía antigua: fuego, agua, aire y tierra. En el universo de Machado, se confunden las fronteras entre los reinos mineral, vegetal y animal (Lopes Dean, Metáfora 93), como lo expresa el siguiente aforismo:

Quando as pedras forem promovidas ao reino vegetal... (CJ 34, cursiva en el original).

Pero ni Bachelard ni Machado entienden este vínculo "sólo en términos físicos y orgánicos, sino dentro de una hermenéutica que interprete el sentido de esa relación como una emoción estética" (Salazar Quintana 4). Así, el individuo de Machado se reconoce a sí mismo en la materia hasta descubrir en ella su verdadero ser:

Moléculas dentro de um turbilhão sem começo nem fim, rolamos anônimos ante a indiferença das coisas. De repente, umas delas - pedra, árvore, gesto, inseto, grito, curva de montanha ou rosto de mulher - qualquer saliência de silêncio - aponta para nós, vem-nos ao encontro e se revela, ao mesmo tempo que nos revela a nós mesmos. E comêçamos a ser (CJ 88). 
El ser mismo del hombre consiste en la dialéctica entre la infinidad del océano y el surgimiento de las emociones estéticas que estructuran el "caos" interior (CJ 17). Salta a la vista que, entre las "coisas" que le permiten al hombre un encuentro consigo mismo, por un lado dominan los objetos de la naturaleza (piedra, árbol, insecto, montaña) y, por otro, los gestos propiamente humanos (gesto, grito, rostro de mujer). Mientras que se ha reprochado al surrealismo de alejar la escritura de la naturaleza, creando lazos artificiales entre las cosas², Machado -junto con René Char y Malcolm de Chazal, aforistas a su vez figura entre los surrealistas que creen en una unión íntima entre el individuo y la naturaleza. Clasificándose "sobre-tudo um surrealista"3, Machado se muestra menos interesado en las extravagancias surrealistas de la creación poética, que en las preocupaciones por el destino humano que ellos heredan de sus predecesores (Pontes 9).

Además, Machado, comparando su “descontinuo interior” con “íntimos arquipélagos" (CJ 17), se funda en la metáfora surrealista del archipiélago, o más precisamente, de la isla. Para Breton y Masson, la isla constituye la masa del peñasco situado en el mar, símbolo de lo infinito y lo indomesticable (Dash 18). Así, el mar entre las islas se ve como lugar de trascendencia del espíritu (Chehab 45) y, en consecuencia, como lugar de creación por excelencia.

Cabe mencionar que, en sus orígenes, el término de archi-pelagos no significaba otra cosa que un mar sembrado de islas. En el centro estaba la continuidad de las aguas que rodeaban las islas y no, como hoy, el conjunto de islas (Joubert 319). A esta noción del archipiélago que se concibe en la terminología griega como espacio abierto, se opone, en la época colonial, la utopía del archipiélago basada en el ideal de la isla pasiva, transparente y gobernable (Dash 18) que será objeto de las ensoñaciones paradisíacas de los primeros navegantes y la dominación colonial en América. Son los surrealistas quienes liberan a la isla de su significado colonial rompiendo la idea del archipiélago como superficie controlable, transformándolo en un espacio misterioso que funciona como intermediario entre el 'yo' y el mundo (Dash 18). Ya no tiene prioridad el espacio transparente, sino las relaciones invisibles que se concretizan en una superficie fragmentada. Para Glissant,

2 En el prólogo a El reino de este mundo, Alejo Carpentier, por ejemplo, compara a los surrealistas con cómitres que crean imágenes artificiales, triviales, desatendiendo lo maravilloso que forma una parte intrínseca do lo real. Vs. también Simonis 271.

Entrevista a Jones Rocha, en Artes y letras, cit. en Lopes Dean, Aníbal Machado 6. 
las relaciones submarinas que entrelazan las islas del Caribe se constituyen gracias a la experiencia del sistema de plantaciones y la esclavitud que sigue persiguiendo las sociedades caribeñas. Así, la historia se transforma en una poética, que Patrick Chamoiseau ha calificado de "etnología surrealista" (Chehab 44). El pensamiento archipélico incluye un momento de resistencia, pues a los esfuerzos de unificación continentales se opone la idea de la pluralidad lingüística, cultural e histórica del archipiélago.

Le monde se créolise, c'est-à-dire les cultures du monde mises en contact de manière foudroyante et absolument consciente aujourd'hui les unes avec les autres se changent en s'échangeant à travers des heurts irrémissibles, des guerres sans pitié mais aussi des avancées de conscience et d'espoir qui permettent de dire - que les humanités d'aujourd'hui abandonnent quelque chose à quoi elles s'obstinaient depuis longtemps, à savoir que l'identité d'un être n'est valable et reconnaissable que si elle est exclusive de l'identité de tous les autres êtres possibles (Glissant, Introduction 15).

Mientras que la poética archipélica de Glissant tiene un carácter colectivo que se manifiesta en la obra individual de cada escritor 'criollo', Machado pone en el centro al individuo y su relación, no solo con la sociedad, sino con todo el universo. Es cierto que Machado deja entrever en sus aforismos cierto anticolonialismo, lo que permite distinguir el uso de un aforismo tomado de René Daumal:

Mais l'Occident individualiste-dualiste-libre-arbitriste, triste, capitalistecolonialiste-impérialiste est couvert d'étiquettes du même genre à n'en plus finir, il est foutu, vous ne pouvez vous douter comme j'en suis sûr (CJ 172).

Sin embargo, no es la voluntad de resistencia postcolonial lo que forma el centro de su pensamiento, sino más bien la resistencia del individuo contra toda forma de opresión:

Cada qual pode mergulhar tranqüilo no fundo de sua cisterna. De repente, porém, o vento do mundo sopra lá em cima, na roda da torre do moinho; é lá vão subindo as águas subterrâneas de nosso ser - sujas, revoltas... (CJ 122).

Aunque la revuelta es asunto de "cada cual”, sobre todo el poeta tiene que liberarse de la presión exterior para conservar la pureza de su poesía: 
Uma ordem social anti-humana e injusta perturba o sono dos poetas. Não querer tomar conhecimento dela é fazer-se cúmplice de uma evasão que humilha e enfraquece a poesia (CJ 166).

Las erupciones del interior del poeta sacan a luz las "imagens de lirismo e revolta” que el autor menciona en el prólogo, es decir, estos íntimos archipiélagos no tienen relación con la imagen colonial de la isla paradisíaca - tal como lo confirma el aforismo "dilatar as fronteiras de nosso espaço interior, não por ocupação colonizadora, mas excitando ao vôo os pássaros nele adormecidos" (CJ 72); sino más bien con la resistencia que también formará parte del pensamiento archipélico de Glissant. Una de las formas de esta revuelta es el humor, rasgo típico de la aforística de Machado y del género en especial:

Humor, rebelião tranqüila do espírito contra a miséria envergonhada da condição humana (CJ 45).

O homem que ri, liberta-se [...] (CJ 162).

El humor figura entre las expresiones de la emoción estética, que, como "saliência de silêncio" sobresale del interior humano, así como las islas de un archipiélago se destacan entre la superficie infinita y uniforme del océano.

Otra forma de resistencia, aún más sutil que el humor, es el sueño. Afiliado al surrealismo, Machado atribuye enorme importancia a lo onírico (Lopes Dean, Aníbal Machado 6), lo que ya se vislumbra en la imagen del pájaro dentro de los adormecidos que hay que capturar al vuelo (CJ 72). En concordancia con la concepción surrealista, el sueño no se percibe como estado de pasividad, sino como fuente de creación artística por excelencia. Toda una serie de aforismos, incluidos en el volúmen Topografía da insônia, que había sido publicado separadamente en 1951 y reeditado dentro de Cadernos de João, dan testimonio del lugar primordial que ocupa el sueño en el pensamiento de Machado:

Pela insônia das noites, vai-se prosseguindo, em delicioso trabalho clandestino, a construção de uma plataforma de espera onde serás recebida com os despojos de tua viagem pelos astros (CJ 36).

Como se describe en este aforismo, si el insomnio no acaba en un viaje imaginario, sumerge al individuo en un estado de esterilidad, o sea, de insensibilidad frente a la emoción estética: 
Quando chegamos a perceber que são as mesmas coisas que se repetem, fingindo de novas - já a insônia está lavrando pelos pontos mais protegidos e em toda a extensão de nosso ser (CJ 118).

Esterilidade da insônia.. Que posso ver ou achar com minha pobre lâmpada de mão, por esses salões excessivamente iluminados? (CJ 121).

O pior momento não é o da morte. O pior momento seria se ela, minutos antes de chegar, nos acordasse do sonho da Vida... (CJ 101, cursiva en el original).

Retomando el famoso título de la obra de Calderón de la Barca, Machado hasta califica la vida misma como sueño, aunque no en el sentido de su fugacidad, sino más bien como continuidad entre el sueño y la realidad adoptada de los surrealistas.

Por último, la rebelión del espíritu se concretiza en la forma poética con que Machado expresa su pensamiento. El aforista brasileño rechaza el verso tradicional, viendo en él una norma que restringe la creatividad del poeta:

Artista do verso, muitas vezes inimigo inesperado da poesia... (CJ 37).

En lugar del verso, opta por toda una gama de géneros cortos que se presentan en un conjunto fragmentario: reflexiones (filosóficas), máximas, microrrelatos, diálogos, descripciones poéticas, retratos de personajes, lecciones para la vida. La pluralidad de los géneros será un rasgo central de la poética del archipiélago, tal y como la entiende Glissant. Su obra traspasa todos los límites de los géneros literarios, constituyendo así una “œuvre en archipel” (Joubert 318), en que cada texto forma una isla, un proyecto literario único que, sin embargo, está relacionado por lazos intertextuales con las demás producciones literarias del autor. De igual manera, los aforismos de Machado, aunque son fragmentos aislados que se pueden leer y entender en forma autónoma, se organizan en archipiélagos cuyas islas se relacionan por lazos temáticos, semánticos, formales y gráficos. En lo que sigue ilustraré cómo se concretiza el pensamiento archipélico en Cadernos de João, clasificando su escritura en dichas categorías. 


\section{LA AFORÍSTICA EN CADERNOS DE JOÃO COMO ESCRITURA ARCHIPÉLICA}

\section{ARCHIPIÉLAGOS TEMÁTICOS Y SEMÁNTICOS}

Los aforismos de Machado dispersos en Cadernos de João se relacionan por motivos que se repiten, funcionando a veces en su sentido literal, otras veces como metáforas. Sin embargo, no solo tienen la función de entrelazar varios aforismos, sino también de estructurar una sola frase. En uno de los aforismos titulados "O verbo no infinito", Machado describe la función de esos motivos de la siguiente manera:

No curso regular da frase pode uma palavra, uma imagem ou um movimento imprevisto assumir a força de uma aparição e iluminar subitamente toda a estrutura verbal. O que era neutro e opaco passa então a irradiar. Como se as palavras esperassem a privilegiada, portadora do elemento mágico que leva a todas a transfiguração da poesia (CJ 20).

Así como la emoción estética, que, según Bachelard, estructura el universo infinito del individuo, una entidad semántica puede asumir un carácter epifánico, revelando el significado de una frase. Y es, precisamente, la fulguración de tal isla semántica lo que eleva la frase al rango de poesía. No obstante, para desplegar su sentido completo, la isla semántica tiene que relacionarse, en una forma archipélica, con otras estructuras verbales por medio de la repetición. Algunos temas que destacan en los aforismos de Machado ya han sido mencionados: espacio y tiempo, la relación del hombre con el universo, la revuelta, el sueño, la poesía y el poeta, la muerte. Además de estos archipiélagos temáticos, Cadernos de João contiene una serie de motivos que aparecen repetidamente, como el pájaro, el sol y el viento, la ciudad, la cárcel, la fiesta y la risa. No obstante, el motivo dominante que inunda los aforismos de Machado es el agua, en la mayoría de los casos en relación con el mar. Presente en constelaciones semánticas diferentes, el agua adopta un sentido complejo que lo vincula tanto con la tranquilidad y la libertad, como con lo misterioso y la turbulencia que conllevan los naufragios. En primer lugar, para Bachelard, el agua es símbolo de la vida: 
Nada mais aflitivo do que um rio seco e uma piscina vazia. Nada que mais relembre a vida que se foi, do que esses dois esqueletos $d a$ água (CJ 86, cursiva en el original).

En el centro del código marítimo de Machado está el movimiento del agua, muchas veces en relación con un navío:

\section{Viajante Sem Passaporte}

Enfim, o que importa é o frêmito da partida; a pista, a praia e a plataforma se afastando... a palpitação das águas no sulco distanciante da popa... (CJ 33, cursiva en el original).

Tanto nos leva ao porto o navio quanto o mar (CJ 31, cursiva en el original).

Todos os navios em todos os mares mal conseguem sustentar o peso da noite que cai sobre as águas (CJ 74).

La desorientación del navío en la noche puede entenderse, en términos poéticos, como falta de puntos fijos dentro de la creación verbal -elementos que constituyen la emoción estética en el espíritu del poeta-, pero también como islas semánticas que permiten una orientación dentro de las constelaciones verbales. Además, el viaje del navío también se puede relacionar con la memoria, otro tema que se repite en los aforismos de Machado.

Esse aglomerado de ossos, vísceras e humores, esse complexo de fibras excitáveis e depósito de memórias - é menos unidade orgânica do que passagem do fluidos, folhas da grande árvore cósmica que liga céus e terra, espírito e sangue, espaço de dentro e espaço de fora em viva transmutação de forças com o Universo.

Ninguém precisa sair de si para participar do ilimitado. Cada cual está perto do longe e contém o Todo, como a gota de água é mar dentro do mar (CJ 54).

Lo que vincula la memoria con la emoción estética es el hecho de que ambas forman parte del Universo que se compara con la infinidad del mar. Y de nuevo estamos de vuelta ante la metáfora del archipiélago. Con tal de que ningún "íntimo archipélago" surja del aglomerado de la memoria, no hay producción artística. Falta un "elemento mágico" para transformar "o que era neutro e opaco" (CJ 20) en poesía. Un poema en prosa titulado "A Bola de 
Agua”, en que Machado retoma la imagen surrealista del peñasco saliendo del mar, ilustra, en forma de microrrelato, la experiencia estética del poeta:

Não terei por muito tempo meu suplemento de terra. Nem mais serei tranqüilo.

Aqui não se ouviam as vagas.

Aqui se esquecia o vulto do navio desaparecido.

Aqui, o mar não era mais que pressentimento de areias e conchas sob os pés.

[...]

Pois foi num dia de canícula que vi surgir do horizonte o bloco de pedra. Surgir e crescer.

E veio avançando em direção à minha cabeça.

Vi a parábola do monstro em viagem pelos céus.

Vi seu corpo de safira desmaiada - concreção de mar en poliedro de pedra.

Só o percibi quando arrebentou perto. E borrifou as plantas. E me deixou gosto de sal na boca.

Ó mar, é teu pedaço.

Por menos que eu creia, é teu pedaço - cristal erguido em vôo de pássaro, desmanchando-se em água.

Ameaça ou mensagem?

Ah! por que não segui a sorte do navio? (CJ 140/141).

En la primera parte del poema se presenta un mar tranquilo, cuya inmovilidad se refuerza con la imagen de las conchas vacías en la playa y el olvido del navío desaparecido ya desde hace mucho tiempo. Un día, un peñasco transformado en monstruo deja confuso al yo lírico. No sabe cómo reaccionar ante este encuentro misterioso, a diferencia de su estancia en el pedazo de tierra desierto. Se reprocha haberse instalado en el terreno inmóvil del olvido en vez de seguir el navío, símbolo de la memoria en movimiento.

La paralización del poeta, interrumpida tan abruptamente por la aparición del peñasco mágico, puede aclararse más con la ayuda del aforismo siguiente, que advierte de los descubrimientos de una época tomando preso el pensamiento del individuo:

O pensamento fica prisioneiro por algum tempo de suas últimas descobertas. Estas acabam incorporando-se ao espíritu geral da época e compondo a fisionomia provisória de uma geração (CJ 22). 
El individuo nunca debe conformarse con sus últimos descubrimientos, sino mantener su espíritu vivo:

Não te empenhes na exclusividade do que descobres. Pertence a todos.

Na superfície das águas ou no azul do céu tuas iniciais não se gravam (CJ 81).

De nuevo, Machado recurre a la imagen del mar, alrededor de la cual ha construido una red compleja de significados que se localizan entre los dos polos de la inmovilidad y del movimiento. Cuando la superficie uniforme del océano se rompe por el curso de un navío o el surgimiento de una isla, o sea, cuando el "vento do mundo" sopla por encima de nuestra cisterna, moviendo las "águas subterrâneas de nosso ser" (CJ 122), las aguas tranquilas del universo se agitan produciendo "imagens de lirismo e revolta" que surgen como íntimos archipiélagos.

Machado no solo utiliza la técnica del archipiélago semántico en sus aforismos, sino también en su obra narrativa. Así, el código marinero determina una serie de imágenes que aparecen en los relatos de A morte da Porta-Estandarte e Outras Historias. En el relato O telegrama de Ataxerxes la nostalgia de Esmeralda, la mujer del protagonista, se condensa en la vista de las islas de Pedra Branca, que ve como "capões do mato no chapadão da

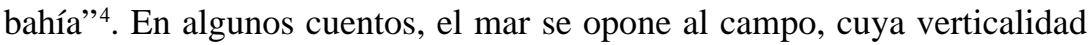
sólida, visible y ascendente puede verse como continuación de la profundidad del mar inconmensurable (Lopes Dean, Metáfora 95) -contraste que Machado retoma repetidas veces en Cadernos de João-, como en uno de sus poemas titulado "Cabeça e rochedo": "Corpo que andavas no campo, agora rolas no mar." (CJ 139), o en el microrrelato "Silêncio na construção": "De um lado era a cidade grande; de outro, o mar sem jangadas" (CJ 91), aunque, en el segundo ejemplo, el cese de la construcción se refleja en la tierra inmóvil de la ciudad y en la tranquilidad del mar sin balsa.

Los ejemplos mencionados de archipiélagos temáticos y semánticos muestran que el archipiélago no solo asume un rol metafórico en la obra de Machado, sino que tiene una función estructurante, función que se manifiesta, por un lado, en la repetición de motivos que aclaran el pensamiento del autor

$4 \quad$ A morte da porta-estandarte e outras historias, Rio: José Olympio Editora, 1965, citado por Lopes Dean, Aníbal Machado 97. 
y, por otro lado, como señalaré en el siguiente párrafo, en los rasgos formales y gráficos que organizan los fragmentos de Cadernos de João.

\section{ARCHIPIÉLAGOS FORMALES}

Aparte de $A B C$ das catástrofes y Topografia da insônia, colecciones de aforismos publicados ya en 1951 e intercalados (en forma revisada y aumentada) en Cadernos de João, hay otros aforismos que, señalados con títulos idénticos, forman un conjunto archipélico. Considero tales grupos de aforismos como archipiélagos formales, ya que están vinculados por designaciones comunes elegidas por el autor que crea así relaciones de significado, uniendo ciertos aforismos dispersos en un mar del conjunto textual. Uno de estos archipiélagos formales, que ya ha sido mencionado, es "O verbo no infinito", conjunto que reúne reflexiones sobre la poesía (vs. las citas más arriba, CJ 20,72) así como breves lecciones:

Partir para a dimensão universal, mas levando no bico ou nas patas o grão de terra com que alimentar o vôo (CJ 73).

Não se apoderar daquilo que se descobre. Nem esconder. Mostrar aos outros. Passar adiante... (CJ 71).

Mostrando diferentes grados de metaforicidad, los dos aforismos citados tienen en común con los demás de su grupo la dialéctica, ya indicada en el título, entre la infinidad o inmovilidad y el impulso ("o grão de terra com que alimentar o vôo”, "Passar adiante”).

Otro pequeño archipiélago formal, creado por el breve título "Se...” reúne dos aforismos que, semejante a "O verbo no infinito", tematizan el impulso de la emoción estética:

Se foi esquecida a obra a que destre ou supões ter dado o melhor de teu gênio e de teu sangue, não fiques ao lado dela como guardião de túmulo, mas como lavrador à espera de que a semente germine (CJ 53).

Se tiveres de deixar uma cidade onde tudo te pareceu diferente e maravilhoso ${ }^{5}$, aconselho-te a não voltar. À segunda visita, e possível

5 Lo maravilloso de Machado, que forma parte de la emoción estética, es una variante de "o insôlito", una categoría de la crítica literaria brasileña que se refiere a todo lo que sorprende, que se aparta de la norma, que supera el horizonte de expectativa, incluido lo supranatural y 
que ela te surja ainda sob a transfiguração poética da primeira. $\mathrm{Na}$ terceira, fugirá definitivamente da luz subjetiva de teus olhos para a aborrecida semelhança com as demais (CJ 67).

En ambos aforismos se aconseja alimentar la emoción estética para mantenerla viva, sea asumiendo una actitud de espera activa, sea impidiendo un efecto de costumbre perjudicial para la percepción subjetiva.

Bajo el título “Os anti-sombra”, Machado reúne dos muy breves aforismos y dos microrrelatos. Sin ocuparme más del contenido de estos fragmentos, cabe destacar que la técnica de los títulos repetidos le permite al autor vincular diferentes géneros literarios bajo una entidad semántica. No obstante, ciertos fragmentos agrupados por un mismo título pertenecen al mismo género, como ocurre en "A atividade dos homens", donde todos los textos son microrrelatos de diferente tamaño. La expresión "atividade” ya indica que en este archipiélago formal no es cuestión de reflexiones filosóficas o metaliterarias, sino de ejemplificaciones concretas de la existencia humana. En el grupo “Os personagens", finalmente, se presentan retratos de personajes concretos, ilustrando otra vez, por medio de ejemplos, la condición humana, que, en los aforismos más concisos y metafóricos, se analiza en un nivel abstracto.

Más allá de la parcial organización de los aforismos de Cadernos de João en grupos, la totalidad de los aforismos que surgen del pensamiento de su autor puede considerarse como un archipiélago formal, sobre todo, si se considera el significado original de archi-pelagos, un mar sembrado de islas. Además, Cadernos de João, como se ha indicado en el párrafo anterior, constituye un archipiélago formal dentro de la obra entera de Machado, destacando entidades semánticas que aparecen en otros contextos de su producción literaria y cuyo significado se alarga en su condensación aforística.

\section{ARCHIPIÉLAGOS GRÁFICOS}

Una tercera forma de archipelización de los aforismos de Machado consiste en la realización técnica de las unidades semánticas creadas por temas,

lo fantástico. Tiene algunos rasgos comunes con el concepto de lo maravilloso en la literatura hispanoamericana (Cândido 1984, advertencia del traductor, 46). Dado que el término de lo maravilloso se ha acunado significativamente por el autor cubano Alejo Carpentier, Machado se acerca, recurriendo a este concepto, una vez más a la literatura caribeña. 
Íntimos arquipélagos: la aforística en Cadernos de João de Aníbal Machado...

145

metáforas, motivos y títulos repetidos. Se trata del aislamiento, y, al mismo tiempo, la conexión de los fragmentos por la técnica del impreso. Así, los aforismos en Cadernos de João están separados por un espacio en blanco, que no marca ni una falta de palabras ni un límite absoluto, sino la dialéctica entre la separación y la relación propia de la poética archipélica. Por un lado, cada aforismo puede leerse y entenderse sin su contexto. Por otro lado, como he mostrado detalladamente, los aforismos están vinculados por lazos semánticos que constituyen el pensamiento del autor. La reunión de estos fragmentos en un libro, que se efectuó en varios pasos -aparte de $A B C$ das catástrofes y Topografia da insônia, los Cadernos encierran la colección Poemas em prosa, publicada por primera vez en 1955- exprime la voluntad de Machado de otorgar al archipiélago de su pensamiento una sustancia material.

Sin embargo, la separación espacial en la página impresa y su reunión en un libro no es el único procedimiento de materialización empleado por el autor de Cadernos. En $A B C$ das catástrofes figura un texto escrito a mano titulado "Desastre no poema" (CJ 139, vs. gráfico), que no solo se recorta sobre el contexto por su carácter manuscrito, sino también por su forma: la disposición de las palabras en grupos que se dispersan por la página recuerdan las islas de un archipiélago en el mar.

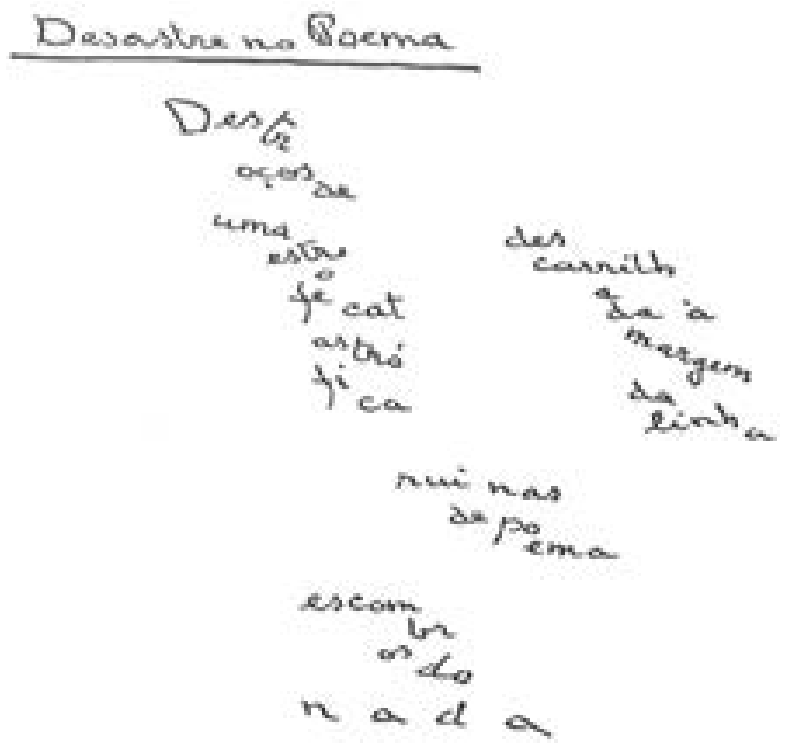


Cuando uno descifra no obstante los pedazos de palabras, nos percatamos de que no se evoca el código marítimo, sino la isotopía de la catástrofe:

\author{
Destroços de uma estrofe catastrófica \\ descarrilhada à margem da linha \\ ruinas de poema \\ escombros do nada (CJ 139, transcripción mía).
}

Sin embargo, no parece casualidad que a este poema le siguen otros dos, en que la imagen del peñasco en el mar es central, entre ellos "A bola de água”, donde el yo lírico, que ha perdido el navío, se ve enfrentado a una roca que surge del mar, convirtiéndose en monstruo. En el aforismo que precede al esbozo, se habla de un "desastre instantáneo" (CJ 138) al que se atribuye "uma fulguração" que no proviene de una fuente de luz exterior. Lo que une "Desastre no poema" con estos poemas vecinos, es lo súbito, lo inesperado, lo fulgurante, que es tan dominante en la obra de Machado y que constituye uno de los rasgos más importantes de la poética archipélica tal y como la formulará Glissant.

\title{
EL AFORISMO COMO GÉNERO ARCHIPÉLICO
}

La aproximación a los aforismos de Machado desde una poética del archipiélago permite la pregunta sobre si el aforismo en general, pero sobre todo en el contexto postcolonial, puede ser considerado como género archipélico, o sea, si la escritura aforística del siglo XX corresponde a lo que Glissant llama el pensamiento archipélico, no sistemático, que explora lo imprevisto de un mundo que se define no por relaciones jerárquicas sino horizontales y que acerca la oralidad a la escritura y viceversa.

Para poder dar una respuesta a esta pregunta, es necesario primero definir lo que se entiende por aforismo. Opto por una definición básica que incluye una pluralidad de variaciones de un género que, desde siempre, se ha mostrado difícil de definir. Entre los teóricos existe en gran parte conformidad sobre el origen del aforismo literario en la edad clásica en el entorno de los moralistas franceses, entre los que destacan La Rochefoucauld, La Bruyère, Chamfort y Vauvenargues. Desde el comienzo, el género del aforismo se despliega en una pluralidad de subgéneros: máximas, sentencias, reflexiones, retratos de personajes. Esta pluralidad va en aumento con la evolución del género. Además, el aforismo aparecía desde el principio no solo dentro de colecciones 
cerradas, sino también dentro de otros géneros como la novela o el drama ${ }^{6}$. Esto significa que el aforismo no siempre constituye un archipiélago gráfico que se recorta sobre su contexto por dichos medios. Sin embargo, siempre se presenta como archipiélago formal que se distingue de su contexto por su mayor concisión, y por no participar de los parámetros de tiempo y espacio del texto circundante. El aforismo sería entonces una frase concisa o un grupo de frases de contenido preciso que forma una unidad de significado independiente, es decir, que se desliga de su contexto sin que este aislamiento deba ser realizado gráficamente. Tal definición incluye también el proverbio, siempre y cuando se presenta en forma escrita, ya que la literariedad es otro de los criterios ampliamente reconocidos del aforismo. De hecho, en las novelas de los autores caribeños contemporáneos o posteriores a Glissant, el aforismo literario, en un sentido estricto, y los proverbios en lengua criolla puestos por escrito y, en su mayor parte, traducidos al francés, van codo a codo o incluso se mezclan, cuando, por ejemplo, un aforismo retoma el metaforismo de un proverbio para integrarlo en una construcción aforística más compleja. Ocurre lo mismo en otras literaturas postcoloniales como en las del África negra. En consecuencia, el aforismo en las literaturas postcoloniales cumple con algunos rasgos importantes del pensamiento archipélico, tal y como lo caracteriza Glissant. No solo relaciona la oralidad (el proverbio) con la escritura (el aforismo literario), sino también incorpora lo inesperado y lo imprevisto. Destacándose formal o gráficamente de su contexto, aparece al mismo tiempo aislado de y relacionado con un conjunto que puede ser una colección de aforismos o un texto de otro género.

Así, el aforismo obedece a la pluralidad de géneros que forman parte del pensamiento archipélico, en un doble sentido. Por un lado, adopta una variedad de formas subgenéricas que, según el teórico alemán André Jolles se derivan de una sola forma simple preliteraria, el dicho: máxima, teorema, sentencia, adagio, proverbio, apotegma (Jolles 156). Se pueden añadir otras formas como el refrán, la greguería, algunos poemas breves y ciertos microrrelatos. Por otro lado, el aforismo se incluye en casi la totalidad de los géneros literarios. Es significativo el hecho de que Glissant mismo incluya aforismos en su obra multigenérica, que ocupa una posición híbrida entre la

6 Así, por ejemplo, en La princesa de Cleves de Madame de La Fayette, o en la comedia de Molière, El misántropo, donde se prestan declaraciones sobre la condición humana en forma de máximas. 
reflexión y la literatura (Helmich, Des pensées 35). Así, la formulación de la poética del archipiélago, en el curso de la obra glissantiana, se vuelve cada vez más intuitiva, axiomática y fragmentaria (Helmich, Des pensées 48). Eso significa que Glissant no solo formula una poética archipélica que otros escritores, como Aníbal Machado, en parte ya han realizado estéticamente, sino que este programa poético tiene su repercusión estética en la obra de su fundador mismo. Cabe mencionar en este punto que Machado no es el único escritor en anticipar la poética del archipiélago dentro del género del aforismo. René Char, en su colección de poemas La parole en archipel (1962), acerca el aforismo a la poesía (Helmich, Der moderne 146-150) creando en su obra un conglomerado de fragmentos, que, separados el uno del otro, se convierten en islas de la memoria y de la sensación (Simonis 275-276).

No es una casualidad que Char, como Machado y Chazal, figura entre los surrealistas que ven la naturaleza de la tierra natal como fuente de su producción estética. Por su carácter fulgurante, el aforismo se presta de manera especial para representar la sensualidad de la isla. Así, Chazal confiesa que no hubiera podido escribir su colección de aforismos Sens-plastique en otro lugar que en las Islas Mauricio, actitud que Khal Torabully, uno de los aforistas mauricianos que siguen los pasos de Chazal, comparte, destacando la luz insular, la forma de la montaña, las flores de vivos colores, el follaje generoso y las frutas (Lay Brander y Torabully 11-12). La naturaleza insular, por lo tanto, estimula la escritura intuitiva, fulgurante y fragmentaria, que es el aforismo.

Otro rasgo que caracteriza el aforismo moderno, no solo en el contexto postcolonial, es la opacidad. Para Glissant, la opacidad forma parte del pensamiento archipélico, recordando a cada individuo el derecho de guardar su misterio psico-cultural, o sea, de mantener la incomprensibilidad de ciertos hechos culturales frente a los que no comparten la misma cultura (Mbom 247). Así, la idea de opacidad se opone a la concepción de lo universal como uno de los fundamentos de la expansión colonial. El género del aforismo, durante su desarrollo desde el siglo XVII hasta nuestros días, ha ido perdiendo su tendencia de universalidad. Mientras que la máxima moralista pretendía formular rasgos universales de la condición humana, aunque sin renunciar a una naciente subjetividad moderna, el aforismo moderno adopta un carácter cada vez más subjetivo (Lay Brander 492-495), que, en la producción aforística contemporánea -y Machado es un vivo ejemplo de ello- se manifiesta en una ocultación consciente del sentido. Más allá de esto, el proverbio, que, en las plantaciones del Caribe colonial formaba parte de un código secreto que 
permitía a los esclavos comunicarse entre sí, sigue manteniendo su función de opacidad en la novela caribeña contemporánea, como por ejemplo en Pluie et vent sur Télumée Miracle (1972) de la autora guadalupana Simone Schwarz-Bart, donde la protagonista Télumée consigue rechazar a su agresor blanco dejándolo perplejo con la ayuda de un proverbio criollo.

En este caso, como en muchos otros, la opacidad del aforismo contiene un momento de combate. Ya hemos visto en Cadernos de João que los aforismos de Machado muestran una tendencia a la resistencia, que también está presente en una gran cantidad de aforismos desde el origen del género. El germanista Gerhard Neumann define el aforismo como frase que se niega al sistema, al orden de pensamiento vigente (8). Aunque esta definición excluye algunas variedades del aforismo, tal y como se entiende aquí, expresa una de las características centrales del aforismo moderno. Chazal, en uno de sus aforismos, lo formula de manera exagerada: "Hay que pensar contra los demás y concluir contra sí mismo”.

Concluyendo, se puede decir que el aforismo en general, debido a su forma, reúne los dos rasgos dialécticos del archipiélago, el aislamiento de la isla representada en el aforismo individual, y su vinculación con un conjunto, en el caso del aforismo elaborado mediante relaciones semánticas y/o gráficas. Además, existe una serie de características que vinculan el aforismo postcolonial y una parte de la producción aforística moderna al programa poético archipélico: el borrar los límites entre oralidad y escritura, el explorar lo imprevisto y lo intuitivo, la sensualidad y la opacidad y, finalmente, un momento de combate. Los Cadernos de João de Aníbal Machado, por consiguiente, pueden considerarse como obra precursora de una escritura aforística postcolonial en que resuena una poética que concibe el mundo en un estado de archipelización.

\section{BIBLIOGRAFÍA}

Bachelard, Gaston. El agua y los sueños. Ensayo sobre la imaginación de la materia. México: Fondo de Cultura Económica, 2003.

Bosi, Alfredo. História concisa da literatura Brasileira. São Paulo: Editora Cultrix, 1994.

Cândido, Antonio. "Die Stellung Brasiliens in der neuen Erzählliteratur Lateinamerikas”. Brasilianische Literatur. Ed. Mechthild Strausfeld. Frankfurt a. M.: Suhrkamp, 1984. 20-46.

Chehab, May. "Poétiques archipéliques: Saint-John Perse et Édouard Glisant”. Transtext(e)s transcultures. Journal of Global Cultural Studies Hors série (2008): 39-48. 
Dash, Michael. “Ile Rocher/Ile Mangrove. Éléments d'une pensée archipélique dans l'œuvre d'Edouard Glissant”. Poétiques d'Edouard Glissant. Ed. Jacques Chevrier. Paris: Presses de l'université de Paris-Sorbonne, 1999. 17-24.

Glissant, Edouard. Traité du Tout-Monde. Paris: Gallimard, 1997.

Introduction à une poétique du divers. Paris: Gallimard, 1996.

Helmich, Werner. "Des pensées en archipel. A propos du statut textuel de la poétique d'Edouard Glissant”. Des îles en archipel... flottements autour du thème insulaire en hommage à Carminella Biondi. Ed. Carmelina Imbroscio/Nadia Minerva/Patrizia Oppici, Bern et al.: Peter Lang, 2008. 35-50.

Der moderne französische Aphorismus. Innovation und Gattungsreflexion. Tübingen: Niemeyer, 1991.

Jolles, André. Einfache Formen. Legende, Sage, Mythe, Rätsel, Spruch, Kasus, Memorabile, Märchen, Witz. Halle/Saale: Niemeyer, 1930.

Joubert, Jean-Louis. “L'archipel Glissant”. Poétiques d'Edouard Glissant. Ed. Jacques Chevrier. Paris: Presses de 1’Université de Paris-Sorbonne, 1999. 317-322.

Lay Brander, Miriam. “La maxime”. Dictionnaire raisonné sur la caducité des formes et des genres littéraires. Ed. Alain Montandon and Saulo Neiva. Genf/Paris: Droz, 2013. 487-498.

Lay Brander, Miriam y Khal Torabully. "Dire la vie de façon kaléidoscopique. Entretien avec Khal Torabully (Ile Maurice) sur l'écriture d'aphorismes". Kreolisierung revisited. Debatten um ein weltweites Kulturkonzept. Ed. Gesine Müller and Natascha Ueckmann. Bielefeld: transcript, 2012. 9-18.

Lopes Dean, Maria A. L. “Aníbal Machado e o Sonho”. Minas Gerais. Suplemento Literário 15.813 (1982): 6-7.

"Metáfora e Prosopopéia: O Universo Animado de Aníbal Machado”. Luso-Brazilian Review 19.1 (1982): 93-109.

Machado, Aníbal. Cadernos de João. Rio de Janeiro: José Olympio, 4ª ed., 2004.

Mbom, Clément. "Edouard Glissant, de l'opacité à la relation". Poétique d'Edouard Glissant. Ed. Jacques Chevrier. Paris: Presses de l'Université de Paris-Sorbonne, 1999. 245-254.

Neumann, Gerhard. "Einleitung”. Der Aphorismus: Zur Geschichte, zu den Formen und Möglichkeiten einer literarischen Gattung. Ed. Gerhard Neumann. Darmstadt: Wissenschaftliche Buchgesellschaft, 1976. 1-18.

Pontes, Mario. “O iniciado do movimento”. Cadernos de João. Ed. Aníbal Machado. Rio de Janeiro: José Olympio, 2004. 7-13.

Salazar Quintana, Luis C. "La fenomenología de la imaginación y la ensoñación creante en Gastón Bachelard”. Synthesis 41 (2007): 41-52.

Simonis, Ferdinand. "Die Lyrik René Chars. Dichtung als Archipel und im Zeichen Orions”. Orbis Litterarum. International Review of Literary Studies 43 (1988): 270-288. 